\title{
LA INSERCIÓN LABORAL DE LOS GRADUADOS DE RELACIONES LABORALES Y RECURSOS HUMANOS DE LA UNIVERSIDAD DE MURCIA
}

\author{
IsABel Barba Aragón \\ Antonio José Carrasco Hernández \\ Departamento de Organización de Empresas y Finanzas. Universidad de Murcia \\ José LuJan Alcaraz \\ Alejandra Selma Penalva
}

Departamento de Derecho del Trabajo y de la Seguridad Social. Universidad de Murcia

Mariano Meseguer de Pedro

Departamento de Psiquiatría y Psicología Social. Universidad de Murcia

Prudencio José Riquelme Perea

Departamento de Economía Aplicada. Universidad de Murcia

DOI: $10.1387 /$ lan-harremanak.15411

\section{ABSTRACT}

El Espacio Europeo de Educación Superior (EEES) ha modificado en profundidad el sistema de formación universitaria. Los estudios universitarios deben construirse en torno a las competencias que exigirá el mercado de trabajo a los egresados. El dominio de las competencias mejora las posibilidades de los individuos que las poseen de encontrar un puesto de trabajo y de ser capaz de mantenerlo o desarrollar 
una carrera profesional a lo largo del tiempo. Asi, surgen interrogantes tras la implantación de los grado, sobre si la formación impartida en los grado, satisface las demandas del mercado de trabajo. Para responder a la pregunta, se ha optado por hacer un análisis de la empleabilidad de los graduados en el mercado de trabajo.

El objetivo del trabajo es analizar la adaptación de los egresados del Grado al mercado de trabajo, en comparación con los egresados de la diplomatura y licenciatura. En total, se ha seleccionado una muestra de 365 egresados para el estudio. Todos los egresados han sido entrevistados a los dos años de finalizar sus estudios.

Palabras clave: Competencias, relaciones laborales, mercado de trabajo, empleabilidad e inserción laboral.

The European Higher Education Area (EHEA) has substantially reformed the system of university education. The university should be built around the competences that the labor market demand for graduates. Competences improve the chances of the individuals who have to find a job and be able to maintain or develop a career over time. Thus, questions arise after the implementation of the degree, on whether the training in the degree meets the demands of the labor market. To answer the question, we have chosen to analyze the employability of graduates in the labor market.

The aim of this study is to analyze the adaptation of the degree alumni in Labor Relations and Human Resources to the labor market, compared to the adaptation of the diploma alumni in Labor Relationas and the degree alumni in Work Science. In total, we selected a sample of 365 graduates for the study. All graduates have been interviewed within two years of completing their studies.

Key Words: Competences, work relationship, labour market, employability, insertion. 


\section{Introducción}

Con la creación del Espacio Europeo de Educación Superior (EEES) se ha modificado en profundidad el sistema de aprendizaje universitario. Los estudios universitarios deben construirse en torno a las competencias que exigirá el mercado de trabajo a los egresados. Es un deber de las instituciones universitarias tomar conciencia de que es parte de su trabajo desarrollar en los estudiantes habilidades personales e intelectuales que les ayuden en el mundo laboral y en la vida en general (CVCP, 1998a). La sociedad percibe la educación superior como un trampolín para alcanzar un buen trabajo en el mercado de trabajo (Lowden et al., 2011). Al menos eso señalan los estudios estadísticos, el $73 \%$ de los estudiantes que participaron en la encuesta ${ }^{1}$ desarrollada en 2010, por la Universidad de Sodexo, reconoció que fue a la universidad para mejorar sus oportunidades de empleo.

En España, las propuestas de estudios universitarios, se han desarrollado por una red de universidades españolas, apoyadas por la ANECA, con la premisa de elaborar guías o libros blancos con los que ayudar al desarrollo de planes de estudio adaptados a las exigencias del Espacio Europeo de Educación Superior (ANECA, 2005). Las universidades tienen que brindar a los estudiantes una formación especializada y más orientada a la empleabilidad del estudiante universitario (Diario Oficial de las Comunidades Europeas, 2001, pp. 104-110).

El modelo de aprendizaje universitario debe establecer unos mecanismos que garanticen que la formación ofertada responde a las necesidades del cambiante mercado laboral (Cajide et al., 2002). En este sentido, los empleadores y egresados están de acuerdo en la importancia de desarrollar las competencias clave (por ejemplo, la comunicación, la capacidad de ver el panorama completo y habilidades críticas / análisis) en los estudios universitarios de grado (Azevedo et at., 2012). La adquisición de estas competencias clave permite a los graduados hacer una transferencia exitosa al mercado de trabajo tras finalizar sus estudios universitarios (Azevedo et al., 2007;. Gomezelj y Azevedo, 2008).

\footnotetext{
1 http://uk.sodexo.com/uken/Images/2010\%20University \%20Lifestyle \%20Survey_ tcm15-424866.pdf
} 
El dominio de las competencias clave mejora las posibilidades de los individuos que las poseen de encontrar un puesto de trabajo y de ser capaz de mantenerlo o desarrollar una carrera profesional a lo largo del tiempo (García y Perez, 2008). Con la formación universitaria basada en competencias, el alumno tiene que mejorar su empleabilidad y su currículum académico en los procesos de selección, y ser más polivalente para cubrir funciones en el mercado de trabajo (Freire, 2009; Losa et al., 2009).

La falta general de investigación que aborde la educación superior en estudios de grado, y en concreto, en el Grado de Relaciones Laborales y Recursos Humanos, hace necesarios estudios que clarifiquen el éxito de los nuevos planes de estudio. Así, tras 10 años desde que se elaboraron los proyectos de Grado y Posgrado, surgen interrogantes sobre si la formación que se imparte en las universidades es la adecuada para satisfacer las demandas del mercado de trabajo (Freire et al., 2013). Para responder a tal pregunta, los escasos trabajos existentes se han agrupado en dos líneas principales. Así cabe destacar, los que han realizado un seguimiento de egresados como vía de análisis de la adaptación exitosa de los universitarios al mercado de trabajo (Montalvo y Ruíz, 2000; Davia, 2004). Otros estudios que se han desarrollado sobre las posibilidades de ajuste universidad-empresa en lo que se refiere a la preparación de los titulados universitarios, concretamente, sobre los perfiles de competencias demandadas por los empleadores y las que proporcionan los títulos universitarios (Ogayar et al., 2008; Gómez, 2010; Almuedo et al., 2011).

Nuestro trabajo encaja en la primera línea de los estudios señalados. Nuestro objetivo es realizar un seguimiento de los egresados como vía de análisis de la adaptación exitosa de los universitarios al mundo laboral. Para ello, se ha realizado un seguimiento de los egresados que finalizaron estudios en el curso 2012/2013, correspondientes a la primera promoción del Grado de Relaciones Laborales y Recursos Humanos, y se les ha comparado con los egresados que finalizaron estudios en la Diplomatura de Relaciones Laborales y en la Licenciatura de Ciencias del Trabajo entre los cursos 2005/2006 a 2010/2011. El objetivo es examinar la evolución de los egresados graduados frente a los egresados de los planes de estudio extinguidos. El éxito de los egresados debe ser mayor en los grado universitarios, diseñados bajo un enfoque de empleabilidad de los estudiantes, que en las diplomaturas y licenciaturas. El estudio se ha construido a partir de la opinión de 365 egresados del grado, de la diplomatura y de la licenciatura..

El trabajo se ha estructurado de forma habitual. En primer lugar se desarrollan los aspectos teóricos. Posteriormente se describe la metodología empírica - muestra, medida de variables y análisis estadísticos - y se presentan los resultados para, por último, exponer y discutir las principales conclusiones del estudio. 


\section{Egresados universitarios: transición al empleo}

Dentro de la Unión Europea, en los diferentes países miembros se ha asumido que es necesario contribuir al desarrollo de un modelo educativo más orientado al mercado de trabajo. Las instituciones universitarias deben tomar conciencia de que es parte de su trabajo desarrollar en los estudiantes habilidades personales e intelectuales que les ayuden en el mundo del trabajo y en la vida en general (CVCP, 1998a). Una formación orientada a las competencias requeridas en el mercado de trabajo mejora la competitividad de la economía, la empleabilidad de los graduados y el ajuste a las necesidades de los empleadores y de sus empresas (CVCP, 1988b). Esta preocupación por la necesidad de que los planes de estudio universitarios ofrezcan títulos centrados en la adquisición de competencias en los estudiantes que incrementé su empleabilidad, se pone de manifiesto en trabajos como el de Martínez (2009) donde se analiza la importancia del sistema educativo en la mejora de la empleabilidad.

En España, desde la década de los 80, en los debates nacionales sobre los planes de estudio en Educación Superior, se ha insistido no sólo en el desarrollo de capacidades académicas e intelectuales, sino también, en la potenciación de las prácticas para prepararles para el empleo y dar respuesta a las necesidades sociales (Cajide et al., 2002). Esta preocupación por la empleabilidad de los graduados se hace patente en el Real Decreto 1393/2007 de 29 de octubre, por el que se establece la ordenación de las enseñanzas oficiales que dota de una importancia central al desarrollo de las competencias clave, aquellas necesarias para el ejercicio de una actividad en el mercado laboral (Marzo et al., 2006).

La mayor empleabilidad parte del concepto de la correcta y adecuada transferencia de competencias aprendidas en el contexto de la formación universitaria a la empresa (Jackson y Hancock, 2010). Para analizar la transferencia de competencias al mercado de trabajo, y su efecto en la empleabilidad, puede examinarse, por un lado, el proceso por el que se produce la transferencia de competencias del ámbito universitario al mercado de trabajo, o bien por otro, el resultado final alcanzado con el proceso de transferencia.

Respecto al análisis del proceso de transferencia, diferentes estudios identifican las dificultades para explicar cómo se produce realmente la transferencia (Rogers y Mentkowski, 2004; Austin et al., 2006; Hakel y Halpern, 2005). En este sentido, diferentes teorías se han desarrollado para tratar el proceso de transferencia de las competencias desde el ámbito universitario al mercado de trabajo (ver Jackson y Hancock, 2010). Respecto al resultado del proceso, se puede examinar si las competencias de los titulados universitarios son las adecuadas para satisfacer las necesidades del mercado de trabajo (Freire et al., 2013), realizando un seguimiento a los egresados. 
Jackson (2009), tras revisar una serie de estudios recientes en los EE.UU., Reino Unido y Australia, señala que los empleadores están insatisfechos con las competencias genéricas adquiridas por los graduados universitarios. En otros estudios (Casner-Lotto y Benner, 2006; Peter Hart Research Associates, Inc., 2006) desarrollados en EE.UU. se encuentran resultados similares de insatisfacción de los empleadores con las competencias genéricas adquiridas por los graduados universitarios (por ejemplo, el pensamiento crítico, resolución de problemas, la comunicación, el trabajo en equipo, la apreciación de la diversidad, la ética en el trabajo, la responsabilidad social...).

Dada la creciente preocupación por la empleabilidad de los graduados, se precisan nuevos estudios empíricos con los que comprender mejor y mejorar el desarrollo de competencias en la educación superior. Este tipo de investigación nos permitirá evaluar mejor cómo bien de preparados están los graduados universitarios. El análisis de la opinión de los egresados puede ser crucial para alcanzar nuevas evidencias en el proceso de mejora del sistema universitario. Así, nuestro trabajo se centra en el análisis de los resultados de la transferencia, a partir del análisis de los egresados. En este sentido, consideramos que los resultados de la transferencia son mejores cuando el alumno posee las competencias requeridas por el mercado de trabajo. Para examinar esos resultados, a lo largo del presente trabajo pretendemos conocer las tasas de empleabilidad de los alumnos egresados, su experiencia profesional tras la finalización de sus estudios y su nivel de satisfacción con los estudios universitarios cursados. Además, el éxito del proceso debe ser mayor en los grado universitarios, diseñados bajo un enfoque de empleabilidad de los estudiantes, que en las diplomaturas y licenciaturas.

\section{Metodología}

\subsection{Población y muestra}

El estudio se ha desarrollado sobre una muestra de egresados de la Universidad de Murcia, procedentes de la Facultad de Ciencias del Trabajo, y pertenecientes al Grado de Relaciones Laborales y Recursos Humanos, a la Licenciatura de Ciencias del Trabajo y a la Diplomatura de Relaciones Laborales. Todos los egresados han sido entrevistados a los dos años de finalizar sus estudios. La población total sobre la que obtener la muestra es de 1.422 egresados (ver tabla 1).

Para seleccionar la muestra mínima, se ha considerado el número total de egresado de cada promoción como población independiente y se ha realizado un muestreo aleatorio simple en cada una de ellas. El tamaño de la muestra viene determinado por el error máximo que se consideró adecuado aceptar 
Tabla 1

Población por titulación y promoción

\begin{tabular}{lrr}
\hline & N & \multicolumn{1}{c}{$\%$} \\
\hline Diplomatura en Relaciones Laborales (promociones 2005/2006 y 2006/2007) & 269 & 18,92 \\
Licenciatura en Ciencias del Trabajo (promociones 2005/2006 y 2006/2007) & 122 & 8,58 \\
Diplomatura en Relaciones Laborales (promociones 2007/2008 y 2008/2009) & 295 & 20,75 \\
Licenciatura en Ciencias del Trabajo (promociones 2007/2008 y 2008/2009) & 100 & 7,03 \\
Diplomatura en Relaciones Laborales (promociones 2009/2010 y 2010/2011) & 416 & 29,25 \\
Licenciatura en Ciencias del Trabajo (promociones 2009/2010 y 2010/2011) & 131 & 9,21 \\
Grado en Relaciones Laborales y Recursos Humanos (promoción 2011/2012) & 89 & 6,26 \\
\hline Total & 1.422 & 100,00 \\
\hline
\end{tabular}

Fuente: Elaboración propia.

Tabla 2

Muestra por promociones

\begin{tabular}{lcc}
\hline & $\mathrm{N}$ & $\%$ \\
\hline Diplomatura en Relaciones Laborales (promociones 2005/2006 y 2006/2007) & 56 & 15,34 \\
Licenciatura en Ciencias del Trabajo (promociones 2005/2006 y 2006/2007) & 44 & 12,05 \\
Diplomatura en Relaciones Laborales (promociones 2007/2008 y 2008/2009) & 56 & 15,34 \\
Licenciatura en Ciencias del Trabajo (promociones 2007/2008 y 2008/2009) & 50 & 13,70 \\
Diplomatura en Relaciones Laborales (promociones 2009/2010 y 2010/2011) & 68 & 18,63 \\
Licenciatura en Ciencias del Trabajo (promociones 2009/2010 y 2010/2011) & 46 & 12,60 \\
Grado en Relaciones Laborales y Recursos Humanos (promoción 2011/2012) & 45 & 12,33 \\
\hline Total & 365 & 100,00 \\
\hline
\end{tabular}

Fuente: Elaboración propia.

(10\% por promoción), con un nivel de confianza del $90 \%(\mathrm{~K}=1,65)$ y considerando el peor de los casos, en el que $\mathrm{P}=\mathrm{Q}=0,5$. La muestra final obtenida es de 365 egresados (ver tabla 2 ).

La técnica de recogida de información empleada ha sido un cuestionario estructurado, diseñado específicamente para la elaboración de este estudio, en base a los objetivos planteados en el mismo. La recogida de información ha sido realizada por el Observatorio de Empleo del Servicio de Orientación y Empleo (COIE) de la Universidad de Murcia. 


\subsection{Variables}

En primer lugar, se han introducido diversas variables para analizar el perfil de ingreso de los egresados y los programas de movilidad. Así, se han medido: (1) los tipos de acceso a la universidad, a partir de cuatro categorías (acceso por adaptación, formación profesional, selectividad y otros); (2) la edad de los egresados; (3) la participación en programas de movilidad; (4) los motivos de acceso a la titulación, a partir de siete categorías (vocación, buenas expectativas profesionales, recomendación de familiares y amigos, adquisición de cultura, imposibilidad de cursar otra carrera por la nota de corte, imposibilidad de cursar otra carrera por implicar desplazamiento y otras razones); y (5) el nivel de satisfacción de los alumnos con los servicios de la universidad.

En segundo lugar, se ha medido el grado de satisfacción con la titulación y con la Universidad. Para ello, se ha examinado: (1) el porcentaje de alumnos que volvería a estudiar la misma titulación; (2) las razones que llevaría a escoger otra titulación diferente; y (3) el grado de satisfacción con la orientación profesional de la titulación.

En tercer lugar, se ha examinado la formación realizada por el egresado tras finalizar sus estudios y se ha medido: (1) el porcentaje de egresados que se han seguido formando tras finalizar su titulación; (2) el tipo de formación; (3) la finalidad de la formación; (4) la movilidad geográfica de los egresados; y (5) el lugar de desplazamiento.

En cuarto lugar, se ha medido el acceso al primer empleo con escalas de: (1) momento de acceso; (2) tiempo medio de acceso tras finalizar la titulación; (3) tipo de ocupación desempeñada; (4) categoría laboral del egresado; (5) ocupación desempeńada en el primer empleo; y (6) salario neto mensual.

Por último, se ha medido la situación laboral de los egresados a los dos años de finalizar la titulación. Así se han utilizado escalas para examinar: (1) los egresados que permanecen en su primer empleo; (2) los egresados ocupados a los dos años de finalizar estudios; (3) duración máxima del desempleo; (4) motivos para la situación de desempleo; (5) tipo de contrato de los egresados; (6) tipo de jornada laboral; (7) salario neto mensual; y (8) grado de satisfacción con el empleo.

\subsection{Resultados}

A través del paquete estadístico SPSS v.20, se procedió a realizar el análisis de los resultados. A continuación se presentan los resultados más relevantes de los ítems analizados, estructurados en cinco apartados: (1) perfil de ingreso y programas de movilidad, (2) grado de satisfacción con la titulación y la universidad, (3) formación realizada por el egresado tras finalizar sus estudios, (4) acceso al primer empleo, y (5) situación laboral de los egresados a los dos años de finalizar la titulación. 


\subsubsection{Perfil de ingreso de los egresados y programas de movilidad}

$\mathrm{El}$ acceso de los egresados en diplomatura y licenciatura son similares (ver figura 1), y procedentes mayoritariamente (más del $80 \%$ de los egresados) de la selectividad. En el grado, los tipos de acceso se modifican, el acceso por selectividad se reduce al $50 \%$, mientras que el acceso por adaptación se incrementa al $30 \%$. Esa variación en los accesos al grado modifica el patrón tradicional de edad de los estudiantes. Así, sólo un $24 \%$ de los egresados del grado tiene menos de 24 años (ver figura 2).

Figura 1

Tipo de acceso a la universidad (\%)

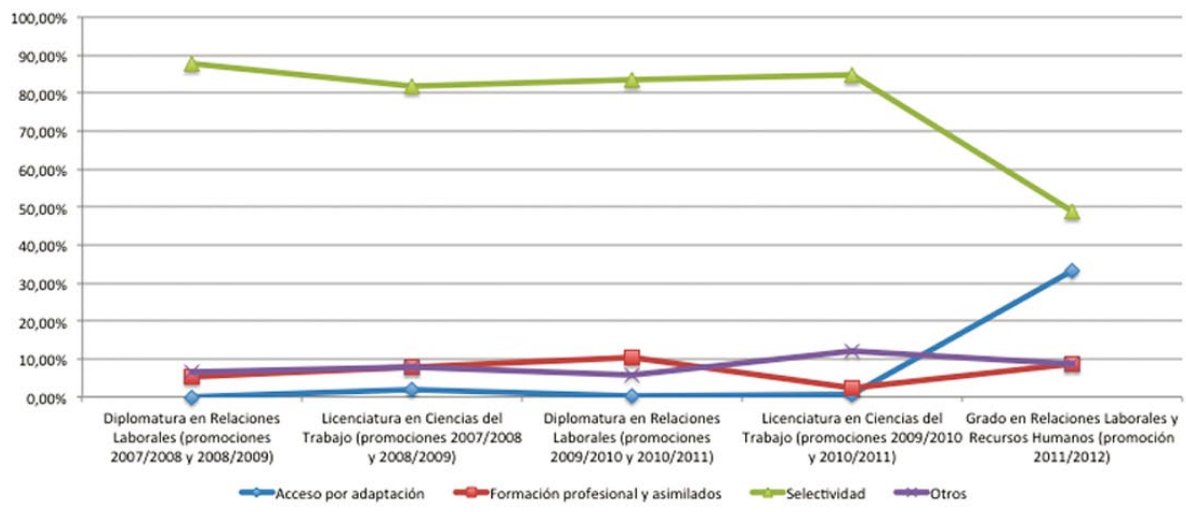

Fuente: Elaboración propia.

Figura 2

Edad de los egresados del Grado

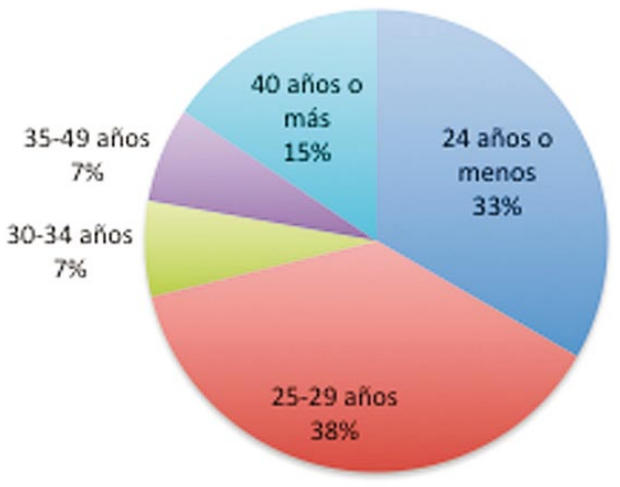

Fuente: Elaboración propia. 
Con relación a los programas de movilidad de los egresados (ver tabla 3), el $13,33 \%$ de los egresados del grado fue formado con programas de movilidad, en la diplomatura y licenciatura, el porcentaje de egresados fue formado con programas de movilidad es mucho menor, excepto en la licenciatura de Ciencias del Trabajo del curso 2009/2010 y 2010/2011, con un porcentaje de movilidad del $9,2 \%$.

Tabla 3

Participación en programas de movilidad

\begin{tabular}{lcc}
\hline & Sí(\%) & $\begin{array}{c}\text { No } \\
(\%)\end{array}$ \\
\hline Diplomatura en Relaciones Laborales (promociones 2005/2006 y 2006/2007) & 1,5 & 98,50 \\
Licenciatura en Ciencias del Trabajo (promociones 2005/2006 y 2006/2007) & 0,8 & 99,20 \\
Diplomatura en Relaciones Laborales (promociones 2007/2008 y 2008/2009) & 4,4 & 95,60 \\
Licenciatura en Ciencias del Trabajo (promociones 2007/2008 y 2008/2009) & 3,0 & 97,00 \\
Diplomatura en Relaciones Laborales (promociones 2009/2010 y 2010/2011) & 2,2 & 97,80 \\
Licenciatura en Ciencias del Trabajo (promociones 2009/2010 y 2010/2011) & 9,2 & 90,20 \\
Grado en Relaciones Laborales y Recursos Humanos (promoción 2011/2012) & 13,33 & 86,67 \\
\hline Total & 52,46 & 47,54 \\
\hline
\end{tabular}

Fuente: Elaboración propia.

En el análisis de los motivos de acceso a la titulación (ver figura 3), encontramos que en la diplomatura y licenciatura de los cursos 2005/2006 y

Figura 3

Motivos de elección de la Carrera

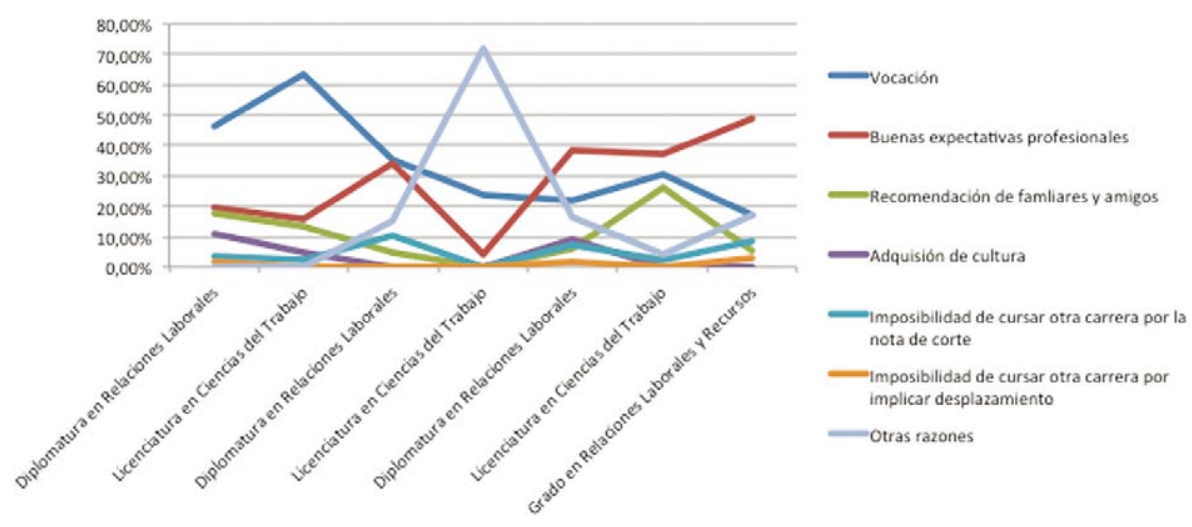


Fuente: Elaboración propia.

2006/2007 predominan la vocación como primer motivo (más del 50\% de los egresados). En los cursos 2007/2008 y 2008/2009 la vocación pierde peso, un $35 \%$ de los egresados entraron a la titulación por ese motivo, mientras que otro $35 \%$ entró a la diplomatura por las buenas expectativas profesionales de la titulación. En la licenciatura, durante esos años, el $73 \%$ de los egresados alegan otros motivos. En los cursos 2009/2010 y 2010/2011, el principal motivo de elección de la diplomatura y licenciatura ( $40 \%$ aproximadamente de los egresados) son las buenas perspectivas profesionales. En el grado de Relaciones Laborales y Recursos Humanos, esas buenas perspectivas profesionales son las que motivaron al $50 \%$ de los egresados a elegir la titulación.

\subsubsection{Grado de satisfacción con la titulación}

La mayoría de egresados (ver tabla 4), más del $50 \%$, estudiaría de nuevo la misma titulación. Tan sólo disminuye ese nivel de satisfacción en los cursos 2009/2010 y 2010/2011, situándose en un 48,5\%. En el grado, el $60 \%$ de los egresados estudiaría nuevamente la titulación.

Tabla 4

Porcentaje de alumnos que volvería a estudiar la misma titulación

\begin{tabular}{lc}
\hline & Total \\
\hline Diplomatura en Relaciones Laborales (promociones 2005/2006 y 2006/2007) & $64,3 \%$ \\
Licenciatura en Ciencias del Trabajo (promociones 2005/2006 y 2006/2007) & $88,6 \%$ \\
Diplomatura en Relaciones Laborales (promociones 2007/2008 y 2008/2009) & $62,5 \%$ \\
Licenciatura en Ciencias del Trabajo (promociones 2007/2008 y 2008/2009) & $58,0 \%$ \\
Diplomatura en Relaciones Laborales (promociones 2009/2010 y 2010/2011) & $48,5 \%$ \\
Licenciatura en Ciencias del Trabajo (promociones 2009/2010 y 2010/2011) & $56,5 \%$ \\
Grado en Relaciones Laborales y Recursos Humanos (promoción 2011/2012) & $60,0 \%$ \\
\hline
\end{tabular}

Fuente: Elaboración propia.

En la figura 4, aparecen las razones para no estudiar la misma titulación. Los egresados que no estudiarían nuevamente la titulación señalan las pocas salidas profesionales como principal motivo en la diplomatura ( $48 \%$ de los egresados) y la licenciatura ( $55 \%$ de los egresados), mientras que en el grado, el principal motivo sería que la carrera no ha cubierto las expectativas que tenían los egresa- 
dos al entrar en la titulación ( $42 \%$ de los egresados). Respecto a la satisfacción con la Universidad, cabe destacar que el 97,05\% de los egresados de grado, estudiaría en la misma universidad.

Figura 4

Razones para no estudiar la misma titulación

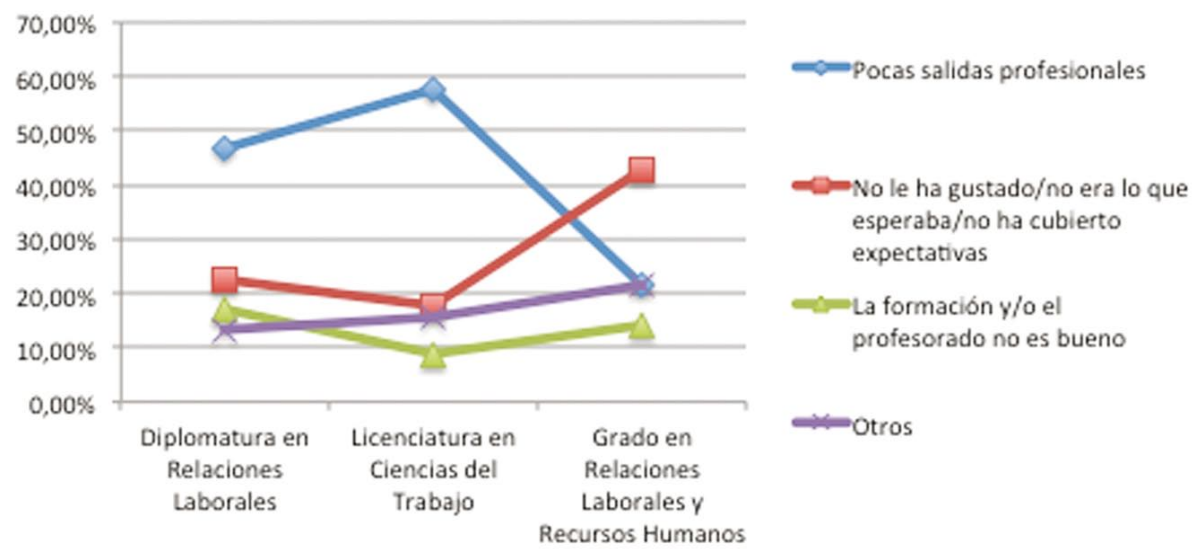

Fuente: Elaboración propia.

\section{Figura 5}

\section{Grado de acuerdo con la orientación profesional de la titulación}

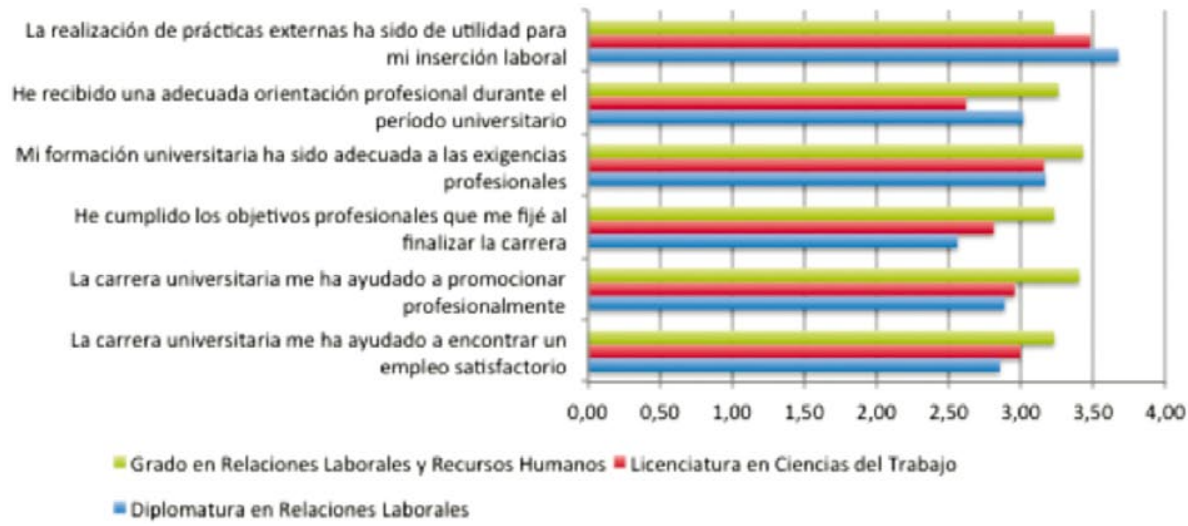

Fuente: Elaboración propia. 
Con los nuevos planes de estudios, adaptados al Espacio Europeo de Educación Superior, se ha potenciado la orientación profesional de los títulos al mercado de trabajo. Así, en la figura 5, el grado de acuerdo de los egresados con la orientación profesional de la titulación en el grado de Relaciones Laborales y Recursos Humanos aumenta respecto a la opinión de los egresados de la diplomatura de Relaciones Laborales y la licenciatura de Ciencias del Trabajo, excepto en la percepción de utilidad de las prácticas externas. En general, la valoración de los egresados a la orientación profesional de las titulaciones es alta, mayor a 2 puntos sobre 4 puntos.

\subsubsection{Formación tras finalizar la titulación y movilidad}

La mayoría de egresados (ver figura 6), más del $70 \%$, ha realizado formación tras finalizar sus estudios universitarios. En el grado, frente a la diplomatura y licenciatura, se reduce el porcentaje de egresados que cursan estudios tras finalizar sus titulación.

Figura 6

Porcentaje de egresados que se han formado tras finalizar la titulación

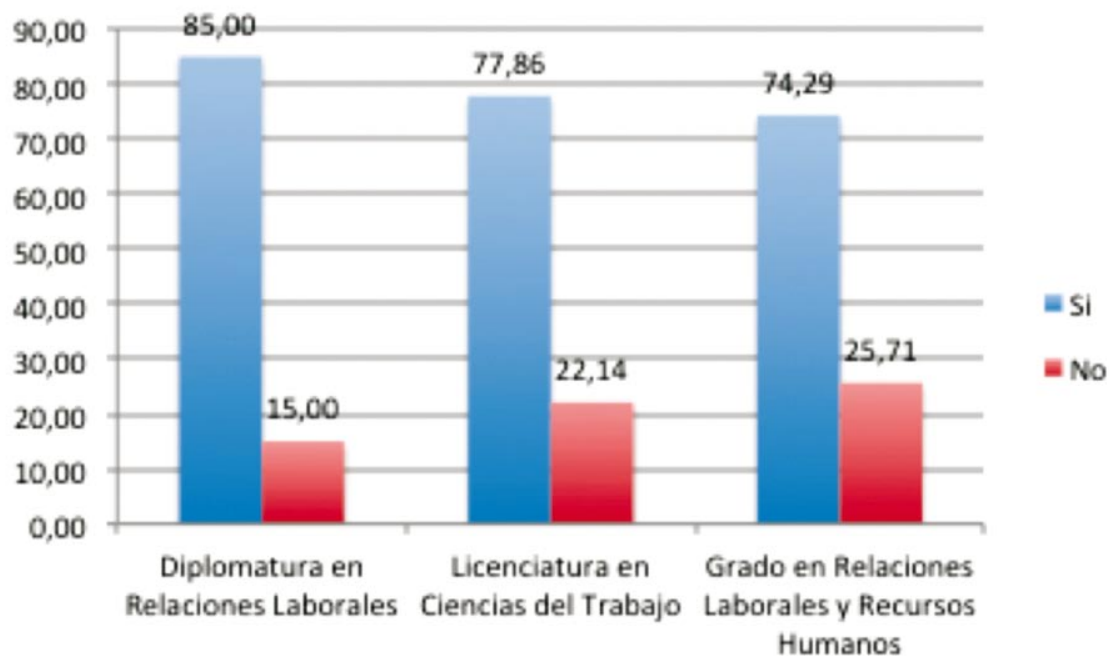

Fuente: Elaboración propia.

En la figura 7, se recogen el tipo de formación escogida por los egresados al finalizar sus estudios. Los alumnos del grado centran su elección en formación de posgrado, en formato de máster (48,57\% de los egresados) o cursos de especialización $(17,14 \%)$, y un $8,57 \%$ de los egresados en realizar otros estudios de grado. La elección de los diplomados es más diversa, repartida entre cur- 
sos de especialista $(33,33 \%)$, máster $(33,33 \%)$, otros estudios universitarios $(18,33 \%)$, estudios de idiomas $(22,22 \%)$ y otras acciones formativas $(24,44 \%)$. Los egresados de la licenciatura centran su elección en estudios de posgrado, en formato de cursos de especialista $(48,57 \%)$ o máster $(40,00 \%)$, o bien en estudios de idiomas $(22,22 \%)$. Cabe reseñar el poco interés de los egresados de grado por cursar estudios de idiomas $(2,86 \%)$.

Figura 7

Tipo de formación realizada por los egresados (\%)

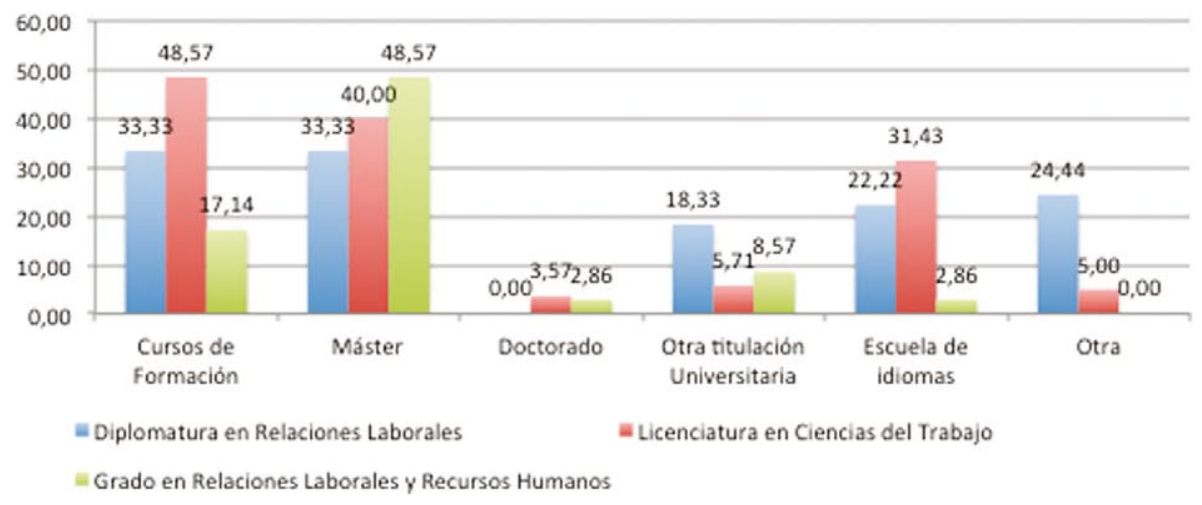

Fuente: Elaboración propia.

Con relación a la finalidad de la formación realizada por los egresados (ver figura 8), en el grado encontramos que la mayoría de los egresados pretende, bien especializarse en alguna rama de la titulación (31,43\% de los egresados) o realizar una formación complementaria que le haga más versátil en el mercado laboral (28,57\% de los egresados). Los diplomados (69,44\% de los egresados) y licenciados ( $40 \%$ de los egresados) prefieren formarse para especializarse en materias de la carrera.

La movilidad geográfica (ver figura 9) de los egresados graduados $(34,29 \%)$ es sustancialmente inferior a la de los egresados diplomados $(46,15 \%)$ y licenciados $(56,79 \%)$. Sin embargo, no se han desplazado porque no han encontrado la oportunidad, ya que son los que se muestran más abiertos a una posible movilidad geográfica $(51,43 \%$ de los egresados graduados). Con relación al lugar geográfico de la movilidad (ver figura 10), los egresados se han desplazado mayoritariamente a otras CCAA (más del $50 \%$ de los egresados), y los egresados graduados son los que se han desplazado en mayor medida a otros países (27,78\%). 
La inserción laboral de los graduados de RelaCiones Laborales y Recursos Humanos DE LA UNIVERSIDAD dE MURCIA

Figura 8

Finalidad de la formación realizada por los egresados ( \%)

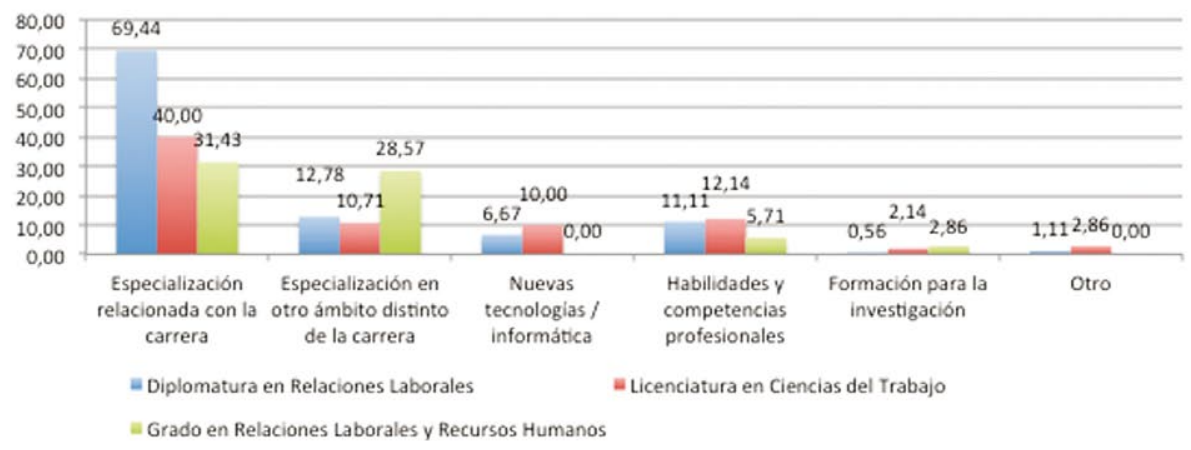

Fuente: Elaboración propia.

Figura 9

Porcentaje de egresados que se han desplazado por trabajo (\%)

Grado en Relaciones Laborales y Recursos Humanos

Licenciatura en Clencias del Trabajo

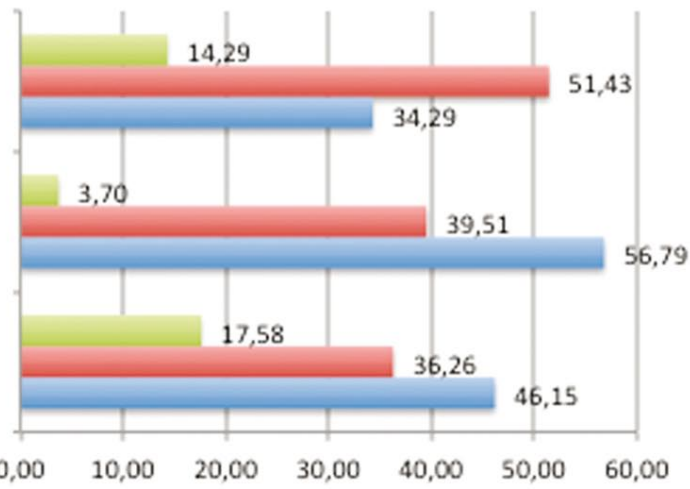

NO, y no lo haría $=$ NO, pero estaría dispuesto a hacerlo $\equiv \mathrm{SI}$

Fuente: Elaboración propia. 


\section{Figura 10}

Lugares a los que se han desplazado geográficamente los egresados (\%)

Grado en Relaciones Laborales y Recursos Humanos

Licenciatura en Ciencias del Trabajo

Diplomatura en Relaciones Laborales

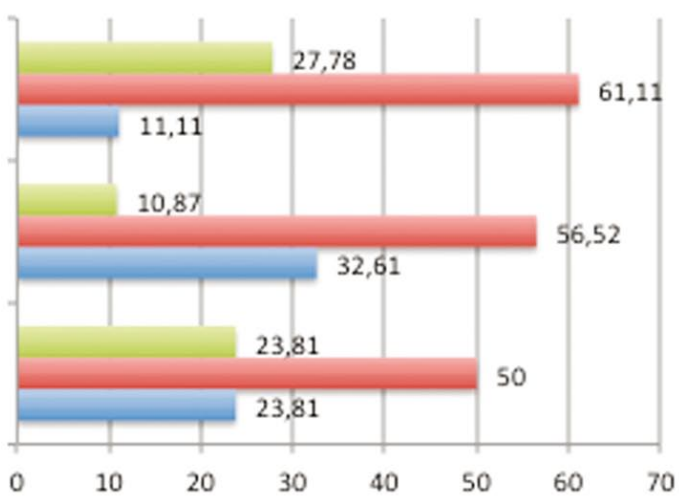

- Otro País = Otra CCAA = Otra localidad lejana en la CCAA

Fuente: Elaboración propia.

\subsubsection{Acceso al primer empleo}

El acceso al primer empleo (ver figura 11), es mayor al finalizar la carrera los egresados ( $40 \%$ o más de los egresados). Una mayoría amplia de los egresados ( $80 \%$ o más de los egresados) señala haber tenido un primer empleo. Los niveles de colocación tras finalizar los estudios han mejorado con el grado y son altos ( $49 \%$ de los egresados). No así, el tiempo medio de acceso al primer empleo que se ha incrementado en el grado de Relaciones Laborales y Recursos Humanos frente a la diplomatura y licenciatura (ver figura 12).

\section{Figura 11}

\section{Momento de acceso al primer empleo del egresado (\%)}

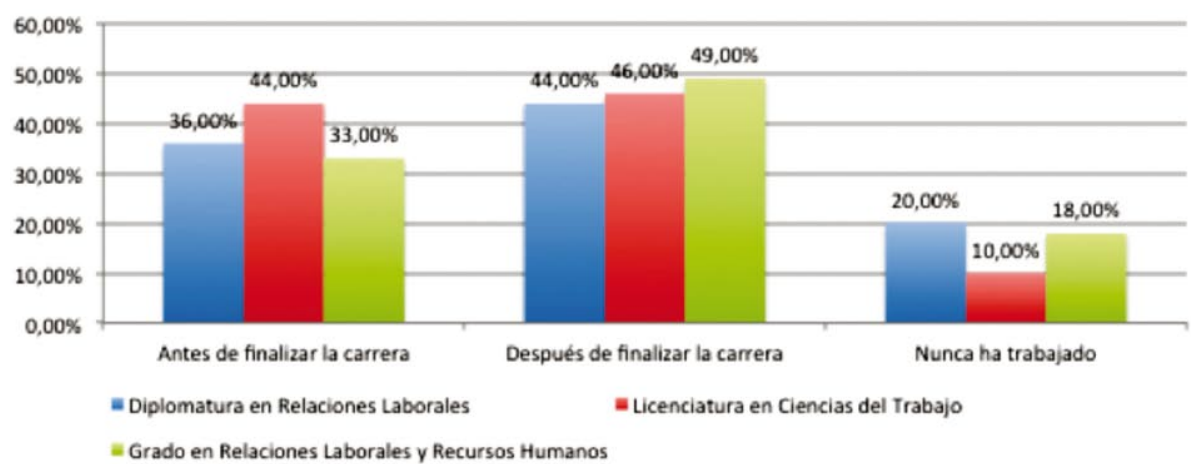

Fuente: Elaboración propia. 
Figura 12

Tiempo medio de acceso al primer empleo tras finalizar título (meses)

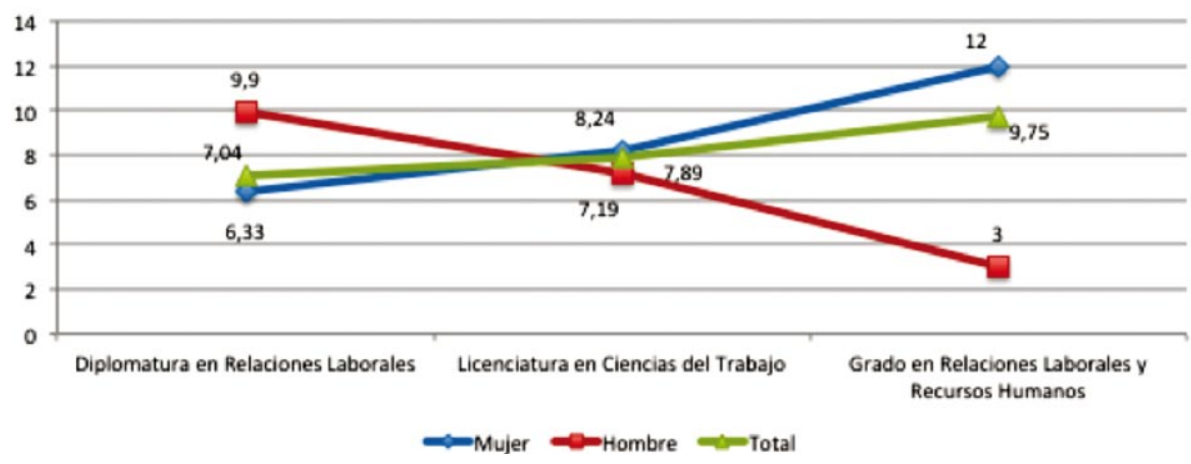

Fuente: Elaboración propia.

En el primer empleo (ver figura 13), los egresados del grado ocupan puestos relacionados con la carrera $(37,14 \%)$ o desempeñando otras funciones administrativas afines $(25,71 \%)$. No obstante, existe un alto número de egresados desempeñando funciones no relacionadas con la carrera $(34,29 \%)$.

\section{Figura 13}

Ocupación desempeñada en el primer empleo por los egresados del grado de Relaciones Laborales y Recursos Humanos

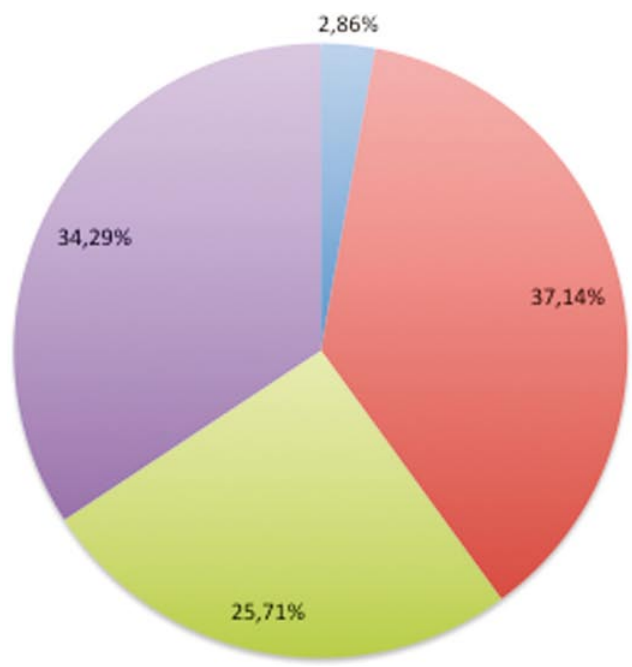

= Emprendedor

Fuente: Elaboración propia. 
Respecto a la categoría laboral de los egresados (ver figura 14), el mayor número de egresados han sido contratados en categoría laboral apropiada ( $40 \%$ o más de los egresados). No obstante, un número alto de egresados ha sido contratado en categoría laboral de menor rango ( $20 \%$ o más de los egresados) o en categoría laboral que no tiene nada que ver con lo estudiado $(20 \%$ o más de los egresados). Un porcentaje pequeño de egresados en el grado se encuentran en categoría laboral de autónomo (6,06\%). Por último, el salario medio de los egresados en el primer empleo (ver figura 15) es de 700 euros para los diplomados, 800 euros para los graduados y 900 euros para los licenciados.

\section{Figura 14}

\section{Categoría laboral del egresado en el primer empleo}

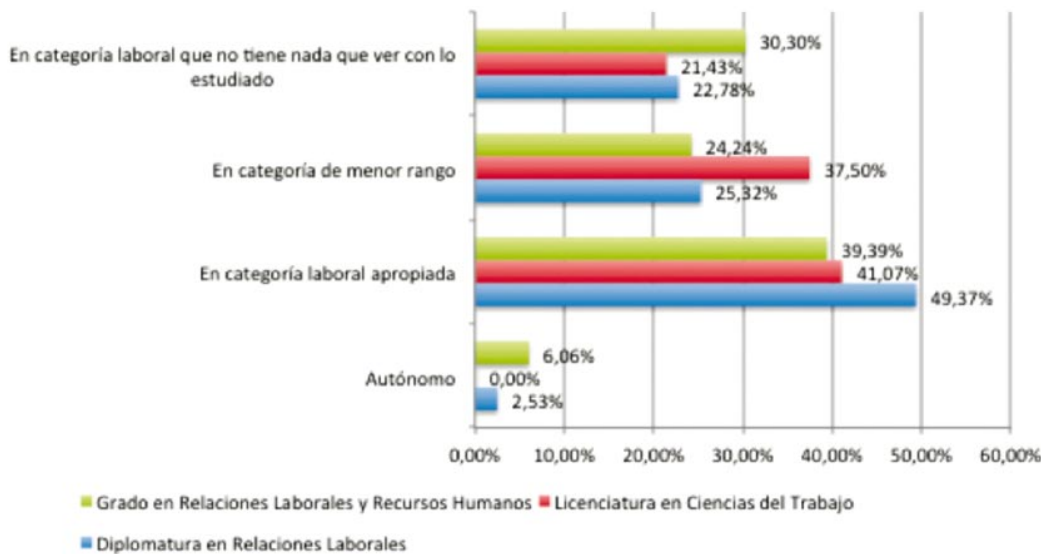

Fuente: Elaboración propia.

Figura 15

Salario neto mensual del egresado en su primer empleo

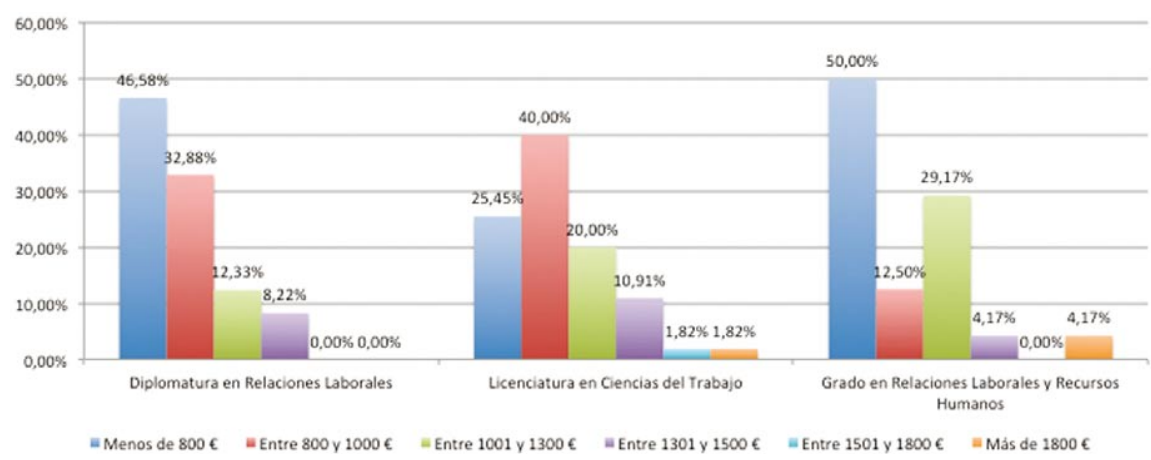

Fuente: Elaboración propia. 


\subsubsection{Situación laboral a los dos años de finalizar la titulación}

Un alto porcentaje de egresados de la diplomatura $(59,89 \%$ de los egresados) y licenciatura $(73,57 \%$ de los egresados) trabaja a los dos ańos de finalizar su estudios (ver figura 16). Entre los egresados ocupados, procedentes de la diplomatura y licenciatura (ver tabla 6), más del $60 \%$ de los egresados permanece ocupado en su primer empleo.

Respecto al grado, señalar que el $65,71 \%$ de sus egresados permanece ocupado a los dos años de finalizar sus estudios (figura 16). Sin embargo, cabe señalar una mayor rotación laboral de los egresados del grado, un 38,71\% de los egresados ocupados del grado permanece en su primer empleo a los dos ańos de finalizar la carrera (tabla 5). Se trata de un dato significativamente inferior al de los egresados de la diplomatura y licenciatura.

Tabla 5

Porcentaje de egresados que permanece en su primer empleo

\begin{tabular}{lcc}
\hline & Sí & No \\
\hline Diplomatura en Relaciones Laborales & $68,29 \%$ & $31,71 \%$ \\
Licenciatura en Ciencias del Trabajo & $59,38 \%$ & $40,63 \%$ \\
Grado en Relaciones Laborales y Recursos Humanos & $38,71 \%$ & $61,29 \%$ \\
\hline Total & $59,89 \%$ & $40,11 \%$ \\
\hline
\end{tabular}

Fuente: Elaboración propia.

Figura 16

Egresados trabajando a los dos años de finalizar el título (\%)

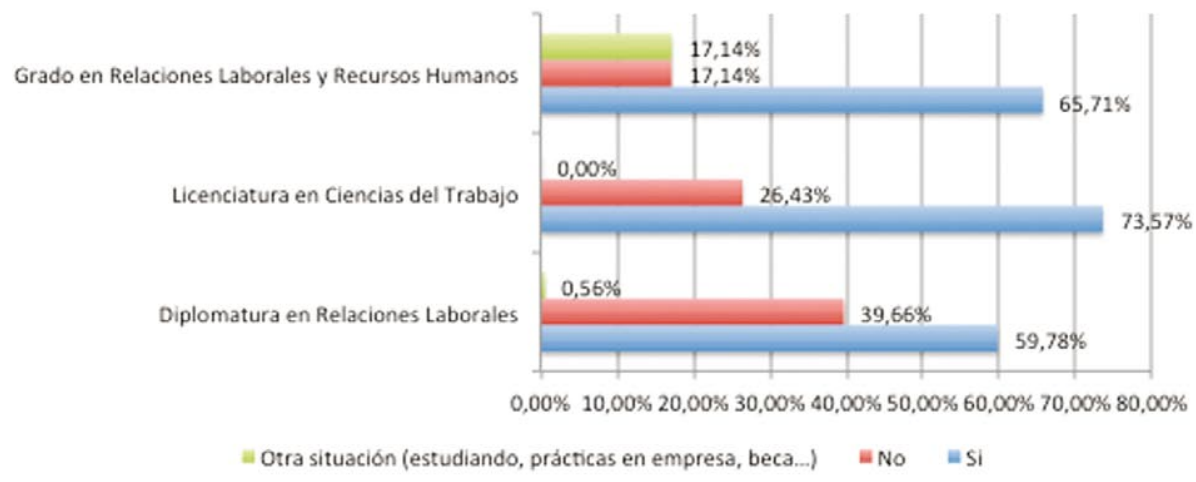

Fuente: Elaboración propia. 
Un análisis de los egresados desempleados del grado (ver figura 17) muestra un desempleo máximo de 6 meses para la mayoría de los titulados $(66,67 \%$ de los egresados). Los motivos principales para el desempleo (ver figura 18) son seguir estudiando (35,71\% de los egresados), buscar empleo y no encontrar (28,57\% de los egresados) u otras razones ( $28,57 \%$ de los titulados). El motivo principal para más del $50 \%$ de los egresados, procedentes de la diplomatura y licenciatura, es buscar empleo y no encontrar.

Figura 17

Duración máxima de desempleo de egresados de grado

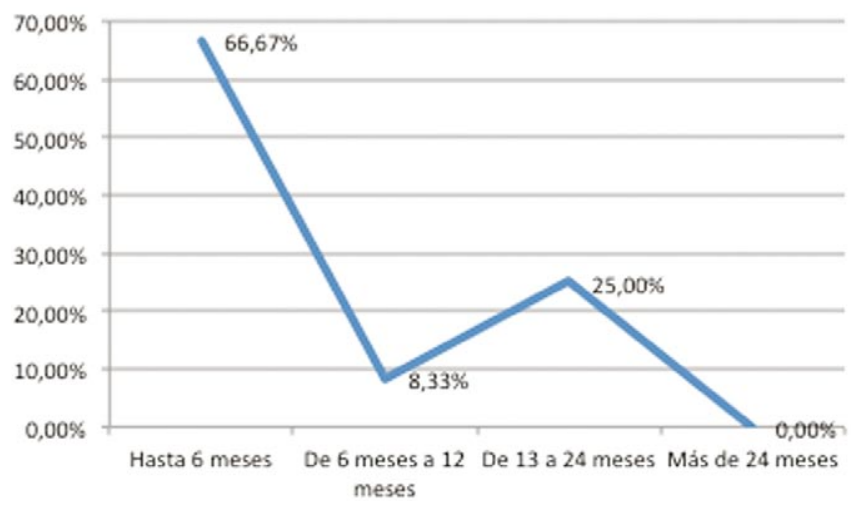

Fuente: Elaboración propia.

Figura 18

Motivo principal al desempleo del egresado (\%)

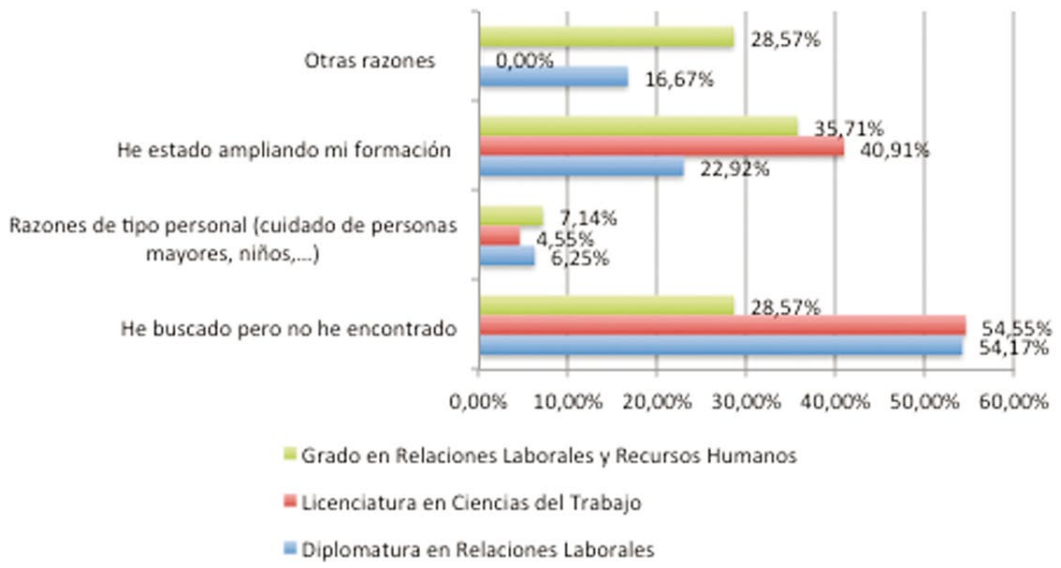

Fuente: Elaboración propia. 


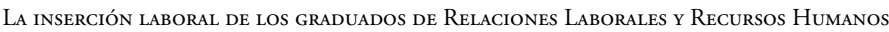
DE LA UNIVERSIDAD dE MURCIA

Figura 19

\section{Categoría laboral del empleo actual del egresado ( \%)}

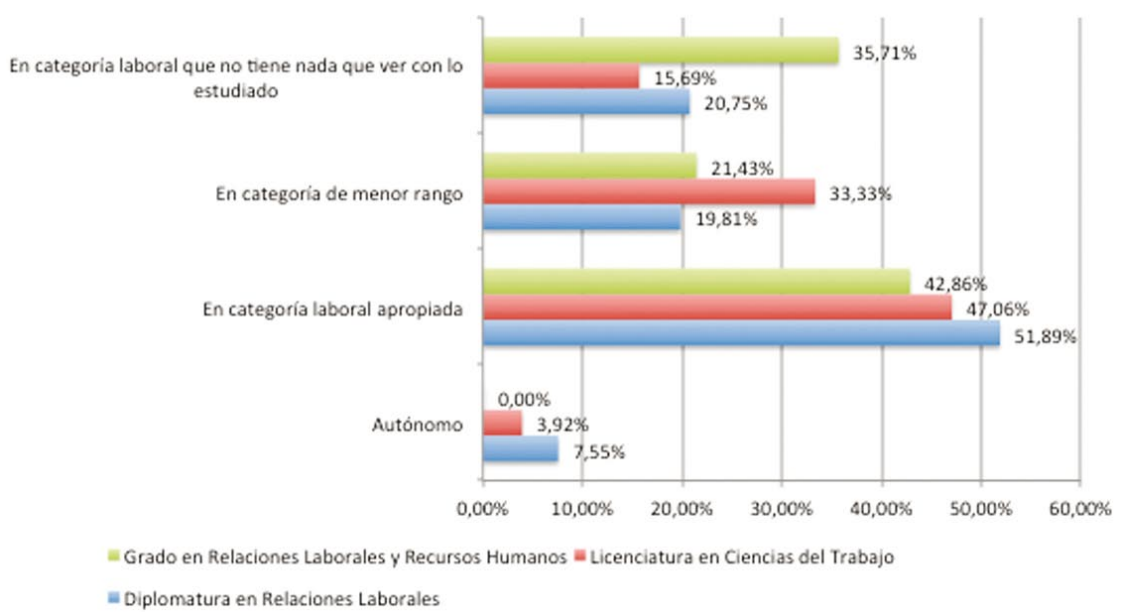

Fuente: Elaboración propia.

Figura 20

Tipo de contrato laboral del egresado (\%)

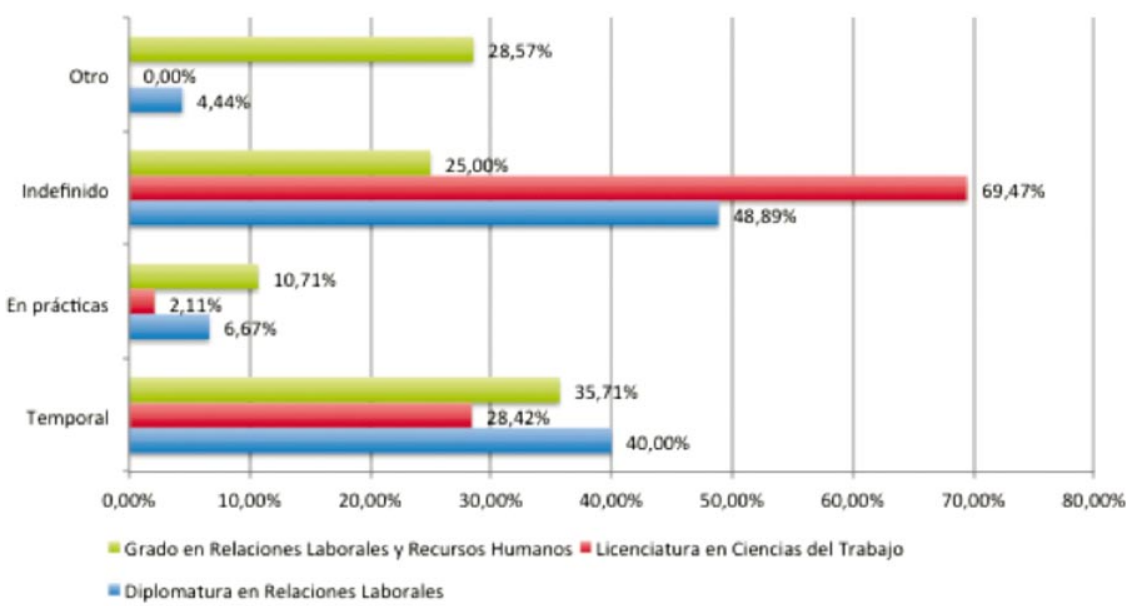

Fuente: Elaboración propia. 
El análisis de los egresados ocupados (ver figura 19) muestra que la mayoría de los diplomados $(51,89 \%)$ aparece contratado en categoría laboral apropiada. El resto de diplomados señala trabajar en categoría laboral de menor rango $(19,81 \%)$ o en categoría que nada tiene que ver con lo estudiado $(20,75 \%)$. La cifra de licenciados contratados en categoría laboral apropiada es sensiblemente inferior a la de diplomados $(47,06 \%)$. El resto licenciados señala trabajar principalmente en categoría de menor rango (33,33\%), y en menor medida, en categoría que nada tiene que ver con lo estudiado (15,69\%). En el grado, un $42,86 \%$ de sus egresados señala que trabaja en categoría laboral apropiada. El resto de graduados, señala trabajar principalmente en categoría que nada tiene que ver con lo estudiado $(35,71 \%)$, y en menor medida, en categoría laboral de menor rango $(21,43 \%)$.

Figura 21

Tipo de jornada laboral del egresado (\%)

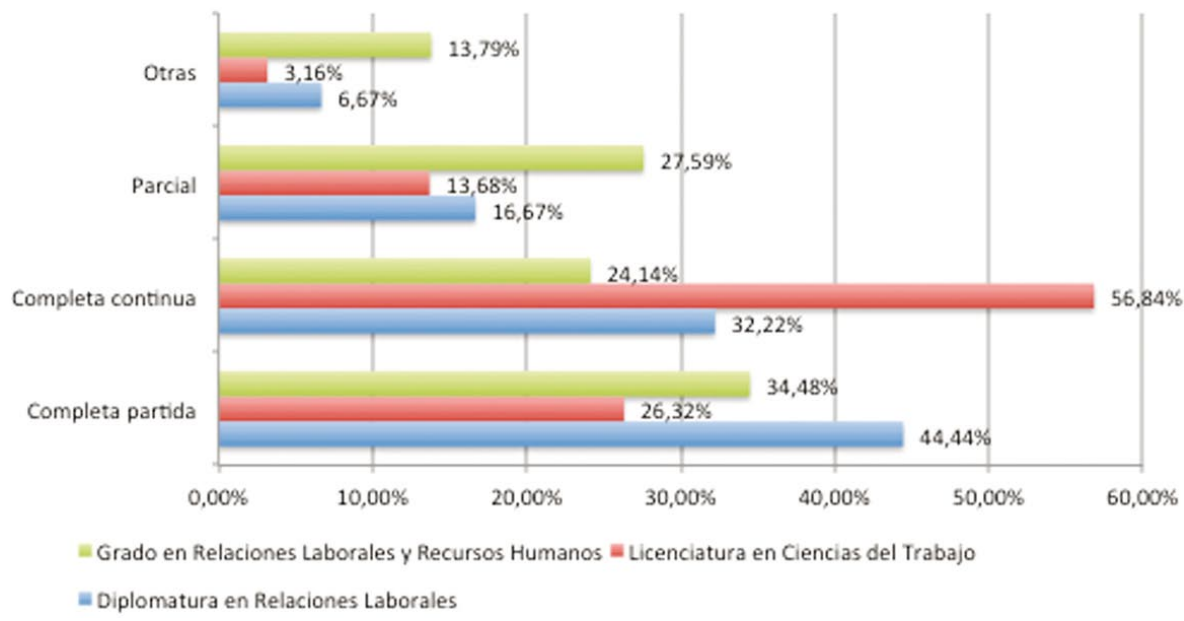

Fuente: Elaboración propia.

El análisis de los tipos de contrato, en el mercado de trabajo (ver figura 20), muestra que la mayoría de los licenciados tiene un contrato indefinido a los dos ańos de finalizar sus estudios (69,47\%), frente al 48,89\% de los diplomados y al 25,00\% de los graduados. La temporalidad de los contratos es mayor entre los egresados, diplomados $(40,00 \%)$ y graduados $(35,71 \%)$, frente a los licenciados $(28,42 \%)$. Un $28,57 \%$ de los egresados graduados señala estar contratado en otras figuras contractuales distintas. Respecto al tipo de jornada laboral (ver figura 21), la mayoría de los egresados señala estar contratado en modalidad de jornada completa. Un $27,59 \%$ de los egresados graduados, señala estar contratado en modalidad de jornada parcial. 
Un análisis de la calidad del trabajo, revela que los egresados están altamente satisfechos con la responsabilidad, los ingresos, las posibilidades de promoción, y la adecuación entre lo estudiado y su empleo actual. Los niveles de satisfacción son similares para los egresados de la diplomatura, licenciatura y grado. Por último, el salario medio de los egresados en el empleo a los dos ańos de finalizar sus estudios (ver figura 15) es de 1.000 euros para los diplomados y graduados y 1.250 euros para los licenciados. El mercado de trabajo ha equiparado el salario de diplomados y graduados.

Figura 22

Salario neto mensual del egresado en su empleo actual

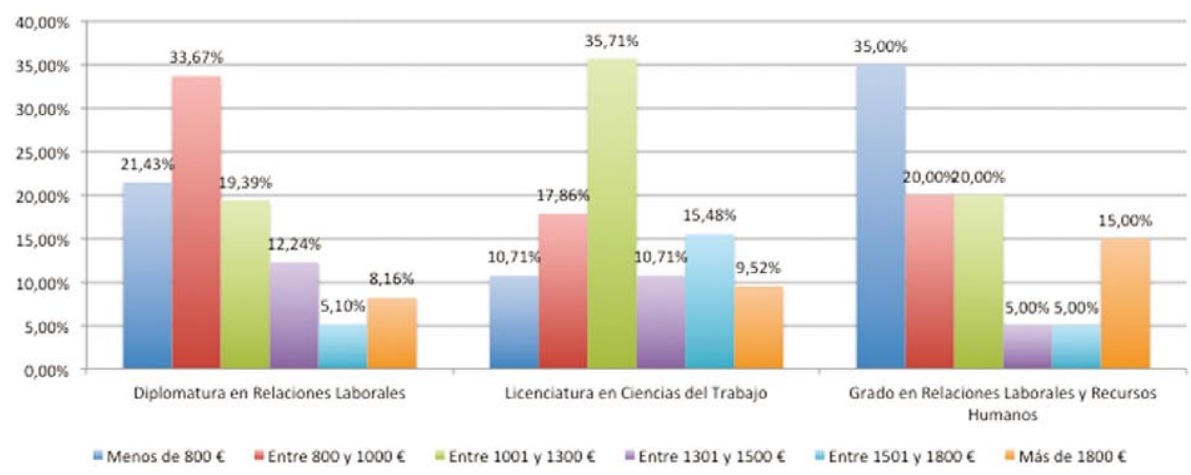

Fuente: Elaboración propia.

\section{Conclusiones}

Con el presente trabajo, se ha realizado un análisis del perfil de egresado del graduado en Relaciones Laborales y Recursos Humanos, y se ha comparado con el de los títulos extintos de diplomado en Relaciones Laborales y licenciado en Ciencias del Trabajo.

En primer lugar, se ha desarrollado un análisis del perfil de ingreso y de los programas de movilidad de los egresados. Así, se ha encontrado que los graduados proceden principalmente de selectividad y de adaptaciones realizadas sobre el grado, mientras que los diplomados y licenciados mayoritariamente de selectividad. Los alumnos egresados entraron a la diplomatura y licenciatura por motivos vocacionales. Sin embargo, con el inicio de la crisis económica, los alumnos egresados demandaban los estudios de grado por motivos relacionados con las buenas perspectivas profesionales.

En segundo lugar, se han medido las perspectivas profesionales del grado. Así, se ha medido el acceso al primer empleo. Una mayoría amplia de los egre- 
sados (80\% o más) señala haber tenido acceso a un primer empleo. La tasa de empleabilidad en el grado, tras finalizar la carrera, es mayor a la de diplomatura y licenciatura. No así, el tiempo medio de acceso al primer empleo que aumenta en el grado, hasta 10 meses de media, frente a los 7 meses de la diplomatura y 8 meses de la licenciatura. El salario medio del graduado, en su primer empleo, es de 800 euros aproximadamente, frente a 700 euros en los diplomados y 900 euros en los licenciados. Cabe reseñar en el primer empleo, un aspecto negativo, ligado a la empleabilidad de los egresados en funciones y categorías laborales que nada tienen que ver con lo estudiado, aproximadamente una tercera parte de los egresados del grado.

En el análisis de la situación laboral en el momento de la entrevista, dos años después de finalizar sus estudios, se encuentra que el $83 \%$ de los graduados se encuentra trabajando o estudiando, cifra superior a la de la diplomatura $(60 \%)$ y licenciatura $(74 \%)$. Otro aspecto que merece la pena reseñar, es la mayor rotación de los graduados en el mercado de trabajo, frente a los diplomados y licenciados. El periodo de desempleo de los egresados del grado, mayoritariamente es inferior a los 6 meses, y variados los motivos de desempleo de los egresados del grado (querer ampliar estudios, buscar trabajo y no encontrar, $\mathrm{u}$ otras razones) frente a los de la diplomatura y licenciatura (buscar trabajo y no encontrar). Los graduados mayoritariamente están contratados a tiempo completo, en diferentes modalidades contractuales (contratos en prácticas, indefinidos, temporales), con un salario neto medio, en 2015, de 1.000 euros, equiparable al del diplomado en Relaciones Laborales, e inferior al de los licenciados. Por otro lado, cabe reseñar un aspecto negativo, ligado a la empleabilidad de los egresados en funciones y categorías laborales que nada tienen que ver con lo estudiado, aproximadamente una tercera parte de los egresados del grado.

En tercer lugar, el grado de satisfacción de los egresados con la titulación y la universidad es muy alto. Los egresados del grado menos satisfechos cambiarían de titulación por cuestiones personales vinculadas a las expectativas del título, mientras que los egresados menos satisfechos de la diplomatura y licenciatura, cambiarían de titulación por cuestiones profesionales vinculadas a la menores salidas del título. En este sentido, el grado presenta una mayor orientación profesional para sus egresados que la que ofrece la diplomatura y licenciatura. Cabe reseñar, por tanto, que los cambios realizados en el sistema de formación universitario, con los grados universitarios, dentro del Espacio Europeo de Educación Superior, han cubierto mejor las exigencias del mercado laboral (Cajilde et al., 2002).

En cuarto lugar, se ha examinado la formación de los egresados tras finalizar sus estudios y su movilidad. Los egresados del grado han optado bien por especializarse en materias relacionadas con la titulación, o realizando una especia- 
lización complementaria en otros ámbitos distintos a la titulación. Las acciones formativas elegidas se han centrado en cursos de especialistas y/o máster. Los egresados procedentes de la diplomatura y licenciatura han optado por una mayor especialización relacionada con la titulación, a través de acciones formativas más variadas (cursos de especialista, máster, otras titulaciones, idiomas...). Respecto a la movilidad, los egresados se han desplazado principalmente a otras CCAA. Los egresados del grado son los que se han desplazado en mayor medida a otros países.

Por último, este estudio no está exento de limitaciones, de la que somos conscientes y que, a su vez, podemos proporcionar líneas fructíferas para la investigación futura. El presente trabajo es un estudio aproximativo, por eso se ha optado por escalas poco validadas. En el futuro, sería adecuado incorporar otro tipo de escalas, y realizar modelos y análisis más complejos.

\section{Bibliografía}

Almuedo, A., Brea, P., Buiza, B., Figueroa, A.R.D.M. y Torres-Olivera, A. (2011). "Utilidad de la acreditación de competencias profesionales en el desarrollo profesional continuo". Revista de Calidad Asistencial, 26(4), 221-227.

ANECA (2005) Libro Blanco del título de grado en Ciencias Laborales y Recursos Humanos [en línea], disponible en web: <http://www.aneca.es/var/media/150308/libroblanco_ rrhh_def.pdf> [Consulta: 27 may. 2015]

Austin, M., Weisner, S., Schrandt, E., Glezos-Bell, S. y Murtaza, N. (2006). «Exploring the Transfer of Learning from an Executive Development Program for $\mathrm{Hu}$ man Services Managers». Administration in Social Work, 30(2): pp. 71-90.

Azevedo, A., Apfelthaler, G. y Hurst, D. (2012). "Competency development in business graduates: An industry-driven approach for examining the alignment of undergraduate business education with industry requirements». The International Journal of Management Education, 10(1), 12-28.

Azevedo, A., Frech, B. y Mueller, C. (2007). "The role of business competencies as supplementing business knowledge: theoretical framework and empirical evidence from a pan-European study of business graduates and employers». In Proceedings of TAQC conference, Bucharest, Romania, 5-14 September 2002.

Cajide, J., Porto, A., Abeal, C., Barreiro, F., Zamora, E., Expósito, A. y Mosteiro, J. (2002). "Competencias adquiridas en la universidad y habilidades requeridas por los empresarios». Revista de Investigación educativa, 20(2), 449-467.

Casner-Lotto, J. y Benner, M.W. (2006). Are they really ready to work? Employers' perspectives on the basic knowledge and applied skills of new entrants to the 21st century U.S. Workforce. USA: the Conference Board, Inc., the Partnership for 21st Century skills, corporate Voices for working Families, and the Society for human resources management.

CVCP, CIHE and CBI (1998a). Helping Students Towards Success at Work: an Intent Being fulfilled, Committee of Vice-Chancellors and Principals, London. 
CVCP, DFEE (1998b). Skills Development in Higher Education Short Report, Committee of Vice-Chancellors and Principals, London.

Davia, M.A. (2004). Tackling multiple choices: a joint determination of transitions out of education and into the labour market across the European Union (No. 2004-22). Institute for Social and Economic Research.

Diario Oficial de las Comunidades Europeas (2001). Dictamen del Comité Económico y Social sobre el tema «Nuevos conocimientos, nuevos empleos» C 14, pp. 103-113.

Freire, M.J. (2009). Competencias profesionales de los universitarios: Competencias profesionais dos universitarios. Consejo Social de la Universidad de A Coruña (Consello Social da Universidade da Coruña).

Freire, M.J., Álvarez, M.M.T. y Montes, C.P. (2013). La adecuación entre las competencias adquiridas por los graduados y las requeridas por los empresarios Adjustment between graduate-acquired and employers-required competencies.

García, J.V. y Perez, M.D.C. (2008). «Espacio Europeo de Educación Superior: competencias profesionales y empleabilidad». Revista Iberoamericana de Educación, 46(9), 4.

Gomez, F. (2010) Competencias profesionales en los titulados UMH. Universidad Miguel Hernández de Elche.

GomezelJ, D.G. y A. Azevedo (2008). "The Relevance of Competencies of Business Study Graduates at the Labour Market». Management, 3: 69-84.

Hakel, M. y Halpern, D. (2005). "How far can transfer go: making transfer happen across physical, temporal and conceptual space». En Mestre, J. (ed.). Transfer of Learning from a modern multidisciplinary perspective. Information Age Publishing: Greenwich, CT.

JACKSON, D. (2009). «Profiling industry-relevant management graduate competencies: the need for a fresh approach». International Journal of Management

Jackson, D. y Hancock, P. (2010). «Non-technical skills in undergraduate degrees in business: Development and transfer». Education, Research and Perspectives, $37(1), 52$.

Losa, N.F., Ortiz, R.F. y SAn Emeterio, M.C. (2009). "Competencias profesionales de los estudiantes y mercado de trabajo. Estudio empírico en la Universidad de La Rioja». En Creativity and survival of the firm under uncertainty (p. 60). Academia Europea de Dirección y Economía de la Empresa, AEDEM.

Lowden, K., Hall, S., Elliot, D. y Lewin, J. (2011). «Employers' perceptions of the employability skills of new graduates». London: Edge Foundation.

Martínez, F.M. (2009). "El proceso de inserción laboral: Implicaciones educativas para mejorar la empleabilidad». Revista Complutense de Educación, 20(2), 455-471.

Marzo, M., Pedraga, M. y Rivera, P. (2006). «Definición y validación de las competencias de los graduados universitarios». Revista de la Educación Superior, 25(4), 140, 49 70 .

Montalvo, J.G. y Ruiz, J.G.M. (2000). «El mercado laboral de los titulados superiores en Europa y en España». Papeles de Economía Española, (86), 111-127.

Ogayar, M.A., Poyatos, R.P. y Solís, J.M.A. (2008). «Competencias profesionales desde el punto de vista de los empleadores, ex alumnos y alumnos de la Universidad de Jaén». En Universidad, Sociedad y Mercados Globales (pp. 437-451). Asociación Española de Dirección y Economía de la Empresa (AEDEM). 
Peter, D. y Hart Research Associates, Inc. (2006). How should colleges prepare students to succeed in today's global economy? Based on surveys among employers and recent college graduates, disponible en web: <http:/www.aacu.org/advocacy/leap/ documents/re8097abcombined.pdf> [Consula: 28 may 2015].

Rogers, G. y Mentкowski, M. (2004). "Abilities that distinguish the effectiveness of five-year alumna performance across work, family and civic roles: a higher education validation", Higher Education Research \& Development, 23(3): pp. 347-74. 